\title{
Tissue Characterization with Gray-level Histogram Width in Obstetrics and Gynecology
}

\author{
${ }^{1}$ Kazuo Maeda, ${ }^{2} \mathrm{PE}$ Kihaile, ${ }^{3} \mathrm{~T}$ Ito, ${ }^{4} \mathrm{M}$ Utsu, ${ }^{5} \mathrm{~N}$ Yamamoto, ${ }^{6} \mathrm{M}$ Serizawa
}

\begin{abstract}
Aim: Clinical ultrasound tissue characterization, using usual B-mode devices.

Materials and methods: Malignant neoplasia in ovary, uterine cervix, and endometrium; placental intervillous space fibrin deposit; fetal growth restriction; fetal brain, fetal lung immaturity; meconium-stained amniotic fluid and healthy adult liver; Tissue was characterized by gray-level histogram width (GLHW) divided by full gray scale length.
\end{abstract}

Results: Malignant GLHW was higher than in benign one (it was malignant if the GLHW was $50 \%$ or more in ovary, uterine cervix, and endometrium). The GLHW of placental fibrin deposit was higher than normal placenta. It was reduced by heparin and normal neonate was obtained. Fetal brain echo density, immature fetal lung, and meconium-stained amniotic fluid were diagnosed by GLHW, and normal adult liver GLHW was studied. Helsinki declaration was followed.

Conclusion: The GLHW tissue characterization objectively diagnosed ultrasound B-mode image in obstetrics and gynecology; thus, it would also be applied in common adult human cases.

Keywords: Fetal growth restriction, Fetal organ, Gray-level histogram width, Liver, Malignancy, Placenta, Tissue characterization, Ultrasound.

How to cite this article: Maeda K, Kihaile PE, Ito T, Utsu M, Yamamoto N, Serizawa M. Tissue Characterization with Graylevel Histogram Width in Obstetrics and Gynecology. Donald School J Ultrasound Obstet Gynecol 2017;11(1):7-10.

Source of support: Nil

Conflict of interest: None

\section{INTRODUCTION}

Although ultrasound B-mode image diagnosis was excellent, objective tissue echogenicity characterization was

\footnotetext{
${ }^{1}$ Honorary Professor, ${ }^{2}$ Postgraduate, ${ }^{3}$ Associate Professor ${ }^{4-6}$ Specialist

1,2Department of Obstetrics and Gynecology, Tottori University Medical School, Yonago, Japan

${ }^{3}$ Department of Obstetrics and Gynecology, Hakuai Hospital Yonago, Japan

${ }^{4,5}$ Department of Obstetrics and Gynecology, Seirei-Mikatahara Hospital, Hamamatsu, Japan

${ }^{6}$ Department of Obstetrics and Gynecology, Hamamatsu Medical Center, Hamamatsu, Japan

Corresponding Author: Kazuo Maeda, 3-125, Nadamachi Yonago Tottoriken, 683-0835, Japan, Phone: +0081859226856 e-mail: maedak@mocha.ocn.ne.jp
}

desired; however, particular computer and programs were mandatory. ${ }^{1}$ Ultrasound B-mode gray-level histogram width (GLHW) achieved clinical tissue characterization in obstetrics and gynecology.

\section{MATERIALS AND METHODS}

The clinical tissue characterization was achieved by GLHW divided by full gray scale length (Fig. 1), ${ }^{2,3}$ of which value was called GLHW, which was standardized by studying RMI 412 phantom (Radiation Measurement Inc., Middleton, Wisconsin, USA), of which histogram width did not change when the B-mode device gain controlled, while image contrast had to be the lowest, because histogram width was enlarged when the image contrast was high. The GLHW of RMI 412 phantom was studied to be standardized in various Aloka machines (Aloka, Tokyo) and Voluson 530D (GE Health care). The GLHW was manually calculated, and also automatically calculated by "\%W" index in the histogram of Aloka B-mode devices (Tokyo), where the value was the same as manual determination. ${ }^{3}$

\section{RESULTS}

\section{Diagnosis of Malignancy}

Ultrasound GLHWs of five connecting regions of interest (ROIs) in preoperative ovarian masses were compared

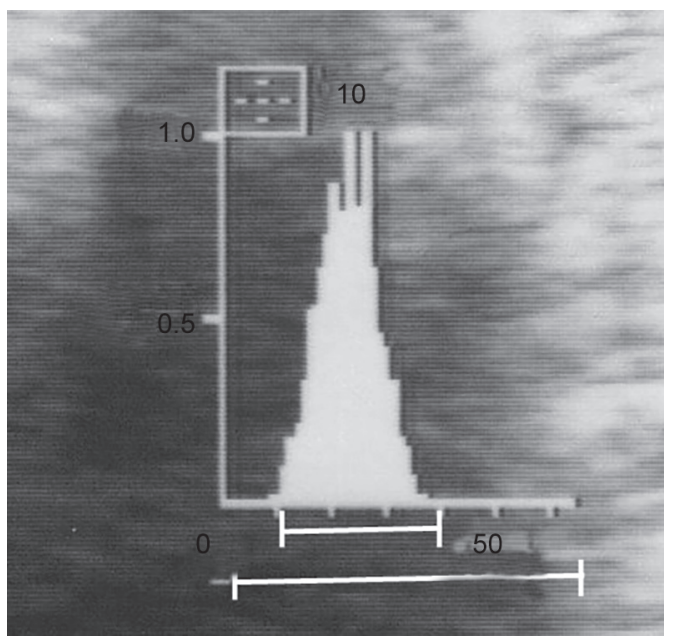

Fig. 1: The calculation of GLHW in the histogram of usual diagnostic ultrasound B-mode device. H: Gray-level histogram width. W: Full gray scale length. $\mathrm{H} / \mathrm{W}(\%)$ is GLHW, which is automatically obtained by the $\% \mathrm{~W}$ index of the ultrasound histogram of Aloka diagnostic B-mode devices 


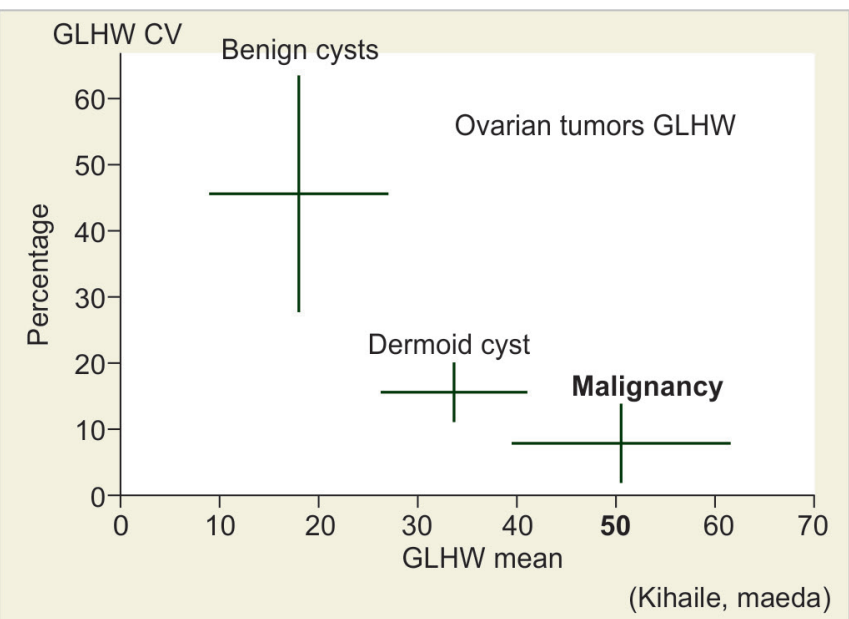

Graph 1: Ovarian tumor GLHW values, which was larger in malignancy than benign one, while coefficient of variation was larger in benign one than malignancy. There was significant difference between GLHW values of benign and malignant ovarian tumors ${ }^{4,6}$

with postoperative pathology in benign and malignant tumors, ${ }^{4}$ where mean GLHW was $18 \pm 10 \%$ in benign masses, while it was $51 \pm 11 \%$ in malignancy, and mean GLHW values were larger in malignant masses than benign tumors (Graph 1), ${ }^{4}$ therefore, ovarian malignant neoplasia is diagnosed by GLHW. Ovarian dermoid cyst was intermediate between benign and malignant masses; however, a dermoid cyst is diagnosed by its characteristic B-mode image, which is the niveau formation.

In other studies, mean GLHW was $42.7 \pm 5.0 \%$ in normal endometrium, while it was $58.2 \pm 11.2 \%$ in endometrial cancer; thus, endometrial cancer will be diagnosed using GLHW. ${ }^{5,6}$

The author found that the GLHW of uterine cervical cancer was higher than $50 \%$. Thus, general malignancy will be indicated if its GLHW is $50 \%$ or more.

Recently, Nam et $\mathrm{al}^{7}$ reported differentiation of malignant and benign thyroid nodules using histogram analysis of gray scale sonograms. Ultrasonic B-mode histogram diagnosis of malignancy was also supported by the report.

\section{Grade 3 Placenta and Intervillous Fibrin Deposit}

The GLHW of $1 \mathrm{~cm}^{2}$ ROI of placental image was manually determined at every two gestational weeks in 20 to 41 weeks of normal pregnancies, where mean \pm 1.5 standard deviation (SD) of GLHW were determined. The GLHW was larger in grade 3 placenta than normal placenta. ${ }^{3}$

\section{Placental Fibrin Deposit in Fetal Growth Restriction Treated by Heparin}

Placental GLHW of a case of intrauterine growth restriction [Fetal growth restriction (FGR)] was larger than that

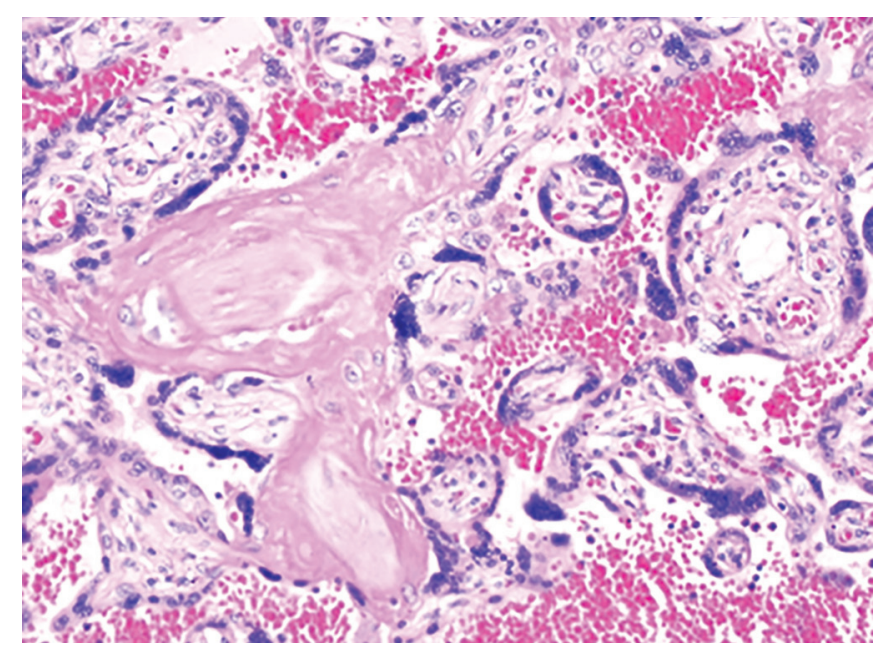

Fig. 2: Microscopic view of a placental intervillous space fibrin deposit. Hematoxylin and eosin, 200x. Courtesy Dr Utsu

of normal placenta and diagnosed by Utsu to be intervillous fibrin deposit (Fig. 2) due to positive cardiolipin antigen in the pregnant woman, and daily 5,000 units of heparin were administered to the woman. The GLHW decreased, estimated fetal weight increased to normal, and normal neonate was obtained (Graph 2), ${ }^{3}$ despite the death of an FGR fetus in a previous pregnancy of the mother in the present study. ${ }^{3}$

\section{DISCUSSION}

The deposited fibrin would reduce placental active transfer of fetal nourishing material developing FGR, and further damaged passive transfer of oxygen would cause fetal demise in previous pregnancy. Heparin solved deposited fibrin to promote placental transfer function and then treated FGR and prevented fetal demise after hypoxia.

\section{Fetal Brain Periventricular Echogenesity}

Yamamoto et $\mathrm{al}^{8}$ studied fetal brain in preterm pregnancy detecting periventricular echodensity (PVE) (Fig. 3), of which $18 \%$ (corresponding $0.2 \%$ of all births) preceded neonatal periventricular leukomalacia (PVL) followed by cerebral palsy (CP), if the PVE lasted until preterm birth, while there was no neonatal PVL when the PVE disappeared before birth. Also, no PVE developed in full-term births' neonates. The GLHW of fetal PVE was $36 \pm 5 \%$, which was significantly larger than $23 \pm 5 \%$ of normal fetal brain GLHW; ${ }^{8}$ thus, GLHW is useful to diagnose fetal and neonatal brain PVE in the prevention of neonatal PVL and CP, namely, the PVE ultrasonically detected immediately after a preterm birth will be effectively treated administrating medicines, e.g., growth factor, erythropoietin, hydrocortisone etc, in the future. 


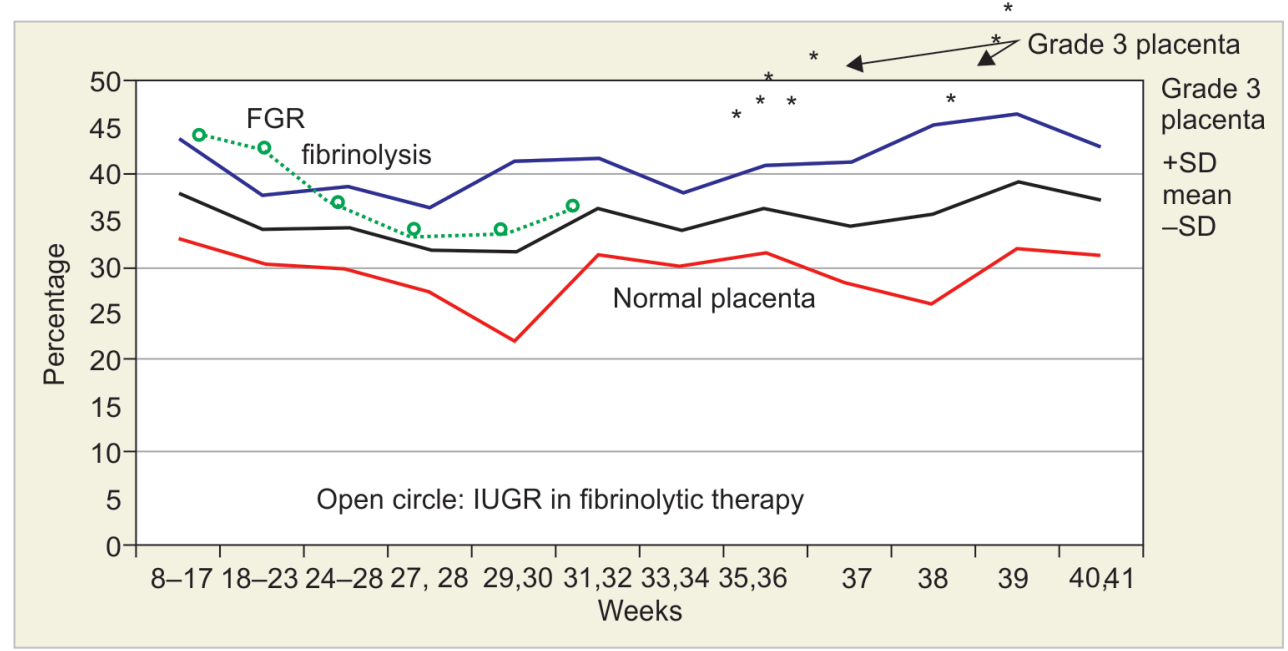

Graph 2: Repeated GLHWs of an FGR (open circles) were compared with normal placental GLHW (mean $\pm 1.5 \mathrm{SD}$ ). High GLHW of the FGR placenta decreased to normal level by the heparin treatment, which soluted fibrin, where estimated fetal weight increased to normal level, and then normal neonate was born

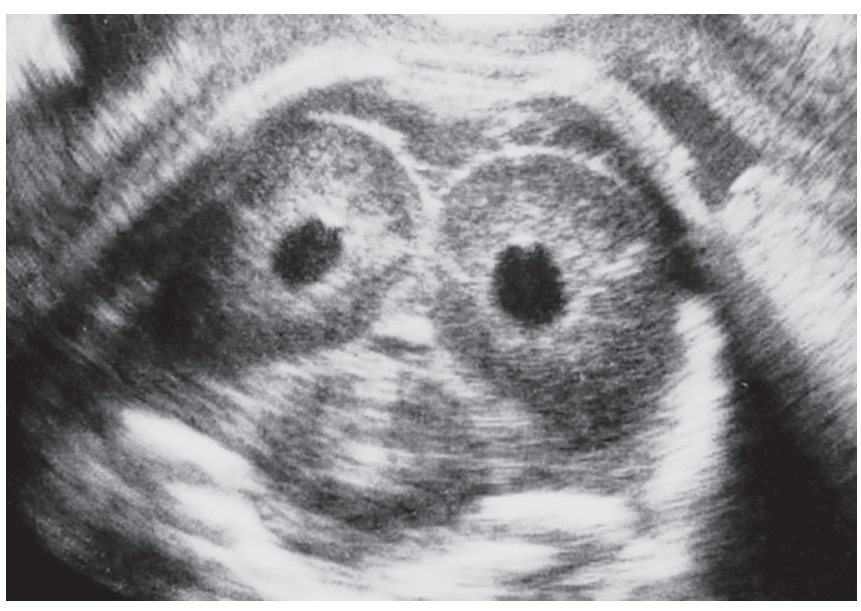

Fig. 3: A case of fetal brain PVE, which has white tissues around fetal ventricles in ultrasound B-mode image. It persisted until preterm birth in the case and then changed to PVL, followed by CP. Courtesy Dr Yamamoto

\section{Diagnosis of Immature Fetal Lung}

Fetal lung maturity should be detected prior to preterm birth to treat the neonate with artificial surfactant to prevent respiratory distress syndrome (RDS). Since the amniocentesis to analyze amniotic fluid for the detection of fetal lung immaturity is invasive in the present perinatal medicine, noninvasive ultrasonic tissue characterization of immature fetal lung has been studied by Serizawa. ${ }^{9-11}$

The GLHW values of fetal lung declined in immature fetal lung, while fetal liver GLHW was constant; the ratio of fetal lung GLHW and fetal liver GLHW was obtained, where fetal lung was immature in young fetus, when the result of gestational weeks multiplied by the ratio of fetal lung to liver ratio was less than 29 , i.e., it was the critical level to divide immature and mature fetal lung, namely,
$96 \%$ of neonatal RDS was predicted by the value lower than 29. The detection rate was highest among various RDS detection parameters. Novel preterm pregnancy management, e.g., maternal steroid administration is monitored by repeated noninvasive GLHW studies. Neonatal surfactant therapy is prepared, or fetal steroid therapy will be repeated, if the fetal lung is still immature with GLHW study. ${ }^{10}$

\section{Diagnosis of Meconium-stained Amniotic Fluid}

Amniotic fluid is a clear fluid accumulated around the fetus in pregnant uterus, which was stained by meconium; fetal stool was released into amniotic fluid in hypoxic fetal asphyxia. The fetus will suffer meconium aspiration syndrom, if the fetus inhales the meconum mixed amniotic fluid. . As the amniotic fluid was stained yellowish dirty by meconium expelled through relaxed fetal anal muscle in asphyxia, amniotic fluid GLHW was higher than clear fluid, and its GLHW was similar to that of fetal colon. Results were confirmed by Maeda et al, ${ }^{11}$ where normal fluid GLHW was $6.7 \pm 2.0 \%$, colon $9.5 \pm$ $2.3 \%$, and meconium-stained fluid $11.0 \pm 3.6 \%$, where significant difference was present between meconiumstained and normal fluids, while the difference was insignificant between colon and stained fluid, and significant between colon and normal fluid. Meconium-stained fluid would be diagnosed by ultrasound GLHW, namely, fetal asphyxia will be detected by GLHW of amniotic fluid.

\section{The GLHW of Healthy Adult Liver}

Mean GLHW of 33 healthy adult livers was $34.8 \pm 3.7 \%$ and its coefficient of variation was $10.5 \%$, where no relation of GLHW was noted to the age or gender. ${ }^{3}$ Therefore, 
pathological state of adult liver is preferable to be studied by its specialists using GLHW, which is determined by the division of histogram base width by full gray scale length in the ultrasound B-mode, or simply by the "\%W" parameter in the Aloka ultrasound B-mode histogram.

\section{CONCLUSION}

Gray-level histogram width is updated clinical ultrasound tissue characterization calculated from ultrasound B-mode echogenicity histogram parameter in a commercial B-mode imaging device. Placental intervillous space fibrin deposit, malignant neoplasia, fetal brain echogenesity, immature fetal lung, meconium-stained amniotic fluid, and normal adult liver were studied, where GLHW was a useful noninvasive clinical tissue characterization using commercial B-mode devices.

\section{REFERENCES}

1. Akaiwa A. Ultrasonic attenuation character estimated from back scattered radio frequency signals in obstetrics and gynecology. Yonago Acta Medica 1989 Mar;32(1):1-10.

2. Maeda, K.; Akaiwa, A.; Kihaile, PE. Ultrasound tissue characterization. In: Chervenak FA, Isaacson GC, Campbell S, editors. Ultrasound in obstetrics and gynecology. Boston, MA: Little Brown; 1993. p. 55-59.
3. Maeda K, Utsu M, Kihaile PE. Quantification of sonographic echogenicity with grey-level histogram width: a clinical tissue characterization. Ultrasound Med Biol 1998 Feb;24(2):225-234.

4. Kihaile PE. Ultrasonic tissue characterization of ovarian tumors by the scanning of grey-level histograms. Yonago Acta Medica 1989;32(3);251-260.

5. Maeda K, Utsu M, Yamamoto N, Ito T. Clinical tissue characterization with gray level histogram width in obstetrics and gynecology. Ultrasound Rev Obstet Gynecol 2002 Apr;2(2):124-128.

6. Ito T, Ishihara K, Deura I, Katagiri C, Maeda K. Tissue characterization of uterine myometrium using the ultrasound gray-level histogram width. Journal of Medical Ultrasonics 2007;34:189-192.

7. Nam, SJ, Yoo J, Lee HS, Kim EK, Moon HJ, Yoon JH, Kwak JY. Quantitative evaluation for differentiating malignant and benign thyroid nodules using histogram analysis of grayscale sonograms. J Ultrasound Med 2016 Apr;35(4):775-782.

8. Yamamoto N, Utsu M, Serizawa M, Ohki S, Murakoshi T, Seguchi M, Iwase K, Maeda K. Neonatal periventricular leukomalacia preceded by fetal periventricular echodensity. Fetal Diag Ther 2000 Jul-Aug;15(4):198-208.

9. Maeda K, Utsu M, Yamamoto N, Serizawa M. Echogenicity of fetal lung and liver quantified by the gray-level histogram width. Ultrasound Med Biol 1999 Feb;25(2):201-208.

10. Serizawa M, Maeda K. Noninvasive fetal lung maturity prediction based on ultrasonic gray level histogram width. Ultrasound Med Biol 2010 Dec;36(12):1998-2003.

11. Maeda K, Serizawa M, Yamamoto N. Ultrasound tissue characterization with the gray level histogram width of the B-mode. Ultrasound Rev Obstet Gynecol 2005;5(2):92-95. 